\title{
Role of Angiotensin-(1-7) via MAS receptor in human sperm motility and acrosome reaction
}

\author{
Asier Valdivia1 ${ }^{1}$ Lorea Cortés², Maider Beitia², Lide Totorikaguena², Naiara Agirregoitia², \\ Beatriz Corcostegui $^{3}$, Luis Casis ${ }^{2}$, Roberto Matorras ${ }^{3,4}$, Jon Irazusta² and Ekaitz Agirregoitia ${ }^{2}$ \\ ${ }^{1}$ Department of Cell Biology, Faculty of Medicine and Nursing, University of the Basque Country, Leioa, Bizkaia, \\ Spain, ${ }^{2}$ Department of Physiology, Faculty of Medicine and Nursing, University of the Basque Country, Leioa, \\ Bizkaia, Spain, ${ }^{3}$ Human Reproduction Unit, Cruces Hospital, Biocruces, University of the Basque Country, Leioa, \\ Bizkaia, Spain and ${ }^{4}$ IVI (Instituto Valenciano de Infertilidad), Bilbao, Bizkaia, Spain
}

Correspondence should be addressed to A Valdivia; Email: asier.valdivia@ehu.eus

\begin{abstract}
Rennin-angiotensin system (RAS) has been involved in sperm function, even so, little is known about the implication of one of the RAS axis formed by Ang-(1-7) (angiotensin-(1-7)) and MAS receptor. Hence, in the present work, we focused on elucidating the function of the MAS receptor in human spermatozoa. We analyzed the expression and localization of MAS receptor in human spermatozoa and we observed if its activation is able to modulate the sperm motility of normal motility and/or asthenozoospermic patients, as well as, the acrosome reaction of the spermatozoa. MAS receptor is present in human mature spermatozoa, not only at the mRNA level but also at protein level. MAS is localized at the acrosome region, as well as, in the tail of spermatozoa. The sperm incubation with MAS agonist Ang-(1-7) activates at dose-dependent manner the PI3K/AKT pathway $(P<0.01$ vs control) and improves the motility of asthenozoospermic patients $(P<0.01$ vs control), which is blocked by the specific antagonist (A779) $(P<0.01)$, but it do not modulate the acrosome reaction. These findings suggest that the ACE2/Ang-(1-7)/Mas axis may be a useful biochemical tool for the treatment of male infertility related to sperm mobility.

Reproduction (2020) 159 241-249
\end{abstract}

\section{Introduction}

RAS (rennin-angiotensin system) is a neuroendocrine cell-communication system which plays a critical role in blood pressure control and body fluid and electrolyte homeostasis. Until very recently, RAS had been seen as a linear limited proteolysis pathway toward the production of a single active end product: Angll (angiotensin II). But nowadays, it has been proposed that RAS could be a dual axis system: on one hand ACE (angiotensin-converting enzyme)/Angll/AT1R (type 1 Angll receptor) axis and, on the other hand, ACE2/Ang-(1-7) (angiotensin-(1-7))/ MAS receptor axis (Santos et al. 2003). Both axes have been involved above all in cardiovascular and renal regulation of the body, but it is known that both of them have pleiotropic effects going far beyond its cardio-renal and vascular actions (Passos-Silva et al. 2013).

Of all of its functions, our interest is focused on the role of RAS in male reproduction, not so much in its vascular actions but on the role that local RAS plays on the spermatozoa. In this sense, the ACE/AngII/AT1R and AT2 $R$ axis have been well described in male human tract and the testis (Passos-Silva et al. 2013) and, specifically in the spermatozoa, both AT1R and ATR2 have been detected from spermatids to mature spermatozoa and it has been proved that the presence of Angl and Angll enhances the motility of human spermatozoa (Vinson et al. 1996, Gianzo et al. 2016).

Regarding the ACE2/Ang-(1-7)/MAS axis, the Ang$(1-7)$ has been detected in the cytoplasm of Leydig cells and in external layers of the seminiferous tubules, particularly in the cytoplasm of Sertoli cells and primary spermatocytes. In addition, MAS receptor was also localized in the cytoplasm of Leydig cells as well as in the seminiferous epithelium, covering its whole extension, from Sertoli cells and spermatogonia to spermatozoa (Reis et al. 2010). Mas-KO mice are fertile, but they have a significant number of apoptotic cells during meiosis, giant cells and vacuoles in the seminiferous epithelium as well as a reduced sperm production per testis and per gram of testis probably due to a disturbed spermatogenesis (Leal et al. 2009). In fact, men with spermatogenesis impairment have lower levels of ACE2, Ang-(1-7) and MAS when they are compared with fertile subjects (Reis et al. 2010).

Up to now, the finding of Ang-(1-7) and MAS within the human seminiferous epithelium raised the possibility that this peptide acts on germ cells, although 
its putative effects remain unknown. So that, we wonder (1) if the MAS receptor is also present in mature human spermatozoa, (2) if it is active and (3) if its modulation could have any effect in the functions of mature spermatozoa as sperm motility or acrosome reaction. In fact, these three will be the objectives of this work.

\section{Materials and methods}

\section{Population}

The population under study consisted of 30 males from infertile couples attending the Human Reproduction Unit from the Cruces University Hospital. Their age ranged 25-40 years.

The inclusion criteria were (1) infertility history $>1$ year, (2) absence of hypertension, infectious or metabolic diseases, (3) BMI <32, (4) no intake of hormonal or antihypertensive treatments in the last 6 months, (5) sperm analysis showing a concentration $>15 \times 10^{6}$ cells $/ \mathrm{mL}$ and normal forms $\geq 4 \%$.

Samples were obtained by masturbation after 2- to 3-day sexual abstinence to perform a standard seminogram as a part of the infertility diagnostic work-up. An aliquot was obtained for the present study. All the participants signed the required informed consent. Ethical approval was obtained from the Ethics Committee of the University of the Basque Country and from the Cruces Hospital Ethics Committee (Register number: CEID/CEISH/61/2011/IRAZUSTA ASTIAZARAN). Kidney samples used as positive controls for some experiments were provided by the Basque Biobank for Research OEHUN (http:// www.biobancovasco.org). All patients were informed about the potential use for research of their surgically rejected tissues, and accepted this eventuality by signing a specific document approved by the Ethical and Scientific Committees of the Basque Country Health System (Osakidetza) (CEIC 11-51).

\section{Sperm sample preparation}

Samples were left $30-45 \mathrm{~min}$ at room temperature for liquefaction before processing. Semen volume, sperm concentration and sperm motility were measured by a computerized sperm-assessment software system, SCA (Sperm Class Analyzer ${ }^{\circledR}$, Microptic, Barcelona, Spain).

\section{Reagents}

Angiotensin (1-7) (Ang-(1-7)) was purchased by Sigma Aldrich and its antagonist A779 by Genscript (Piscataway, NJ, USA).

\section{Incubation assays}

For incubation assays, sperm cells were separated in a unique centrifugation step (1800 g, $15 \mathrm{~min}$ ), as means of washing the seminal plasma, and resuspended in PBS (except for the acrosome reaction experiment that will be explained later) at a minimum concentration of $30 \times 10^{6}$ cells $/ \mathrm{mL}$ checking the absence of other cell types. With the aim of describing the effects of the activation of MAS receptor on the activation of PI3K/AKT pathway, sperm motility and acrosome reaction, the sperm cells were incubated with increasing concentrations of the MAS specific agonist angiotensin (1-7) and its antagonist A779, at different incubation times, at $37^{\circ} \mathrm{C}$, using sterile PBS medium as vehicle. Thus, the isolated sperm cells were divided in six different aliquots, as follows: control (PBS), Ang(1-7) $10^{-8} \mathrm{M}$, Ang-(1-7) $10^{-7} \mathrm{M}$, Ang-(1-7) $10^{-6} \mathrm{M}$, Ang-(1-7) $10^{-7} \mathrm{M}$ and $\mathrm{A} 77910^{-6} \mathrm{M}$, and $\mathrm{A} 7791^{-6} \mathrm{M}$. Sperm cells were pre-incubated with the antagonist A779 for 10 min before the agonist addition. For the assessment of AKT phosphorylation by Western blot, the agonist and antagonist were removed in a brief centrifugation step $(10,000 \mathrm{~g}, 10 \mathrm{~min})$ and the pellets were rapidly frozen in liquid nitrogen.

\section{RT-PCR analysis}

For PCR assays, a swim-up separation technique step was performed before plasma washing, so as to remove nonmotile cells, such as lymphocytes. We used multiple tubes with small volumes of fresh semen $(250 \mu \mathrm{L})$ and $500-600 \mu \mathrm{L}$ sterile PBS buffer above each fresh semen aliquot. After 60-min incubation at $37^{\circ} \mathrm{C}$, most of the upper PBS layer was recovered from each tube and centrifuged at low speed $(600 \mathrm{~g}, 15 \mathrm{~min})$, discarding the supernatant.

The RNA of swim-up recovered spermatozoa was isolated

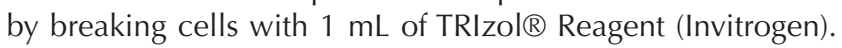
$200 \mu \mathrm{L}$ of chloroform were added and, after 3-min incubation, samples were centrifuged for $10 \mathrm{~min}\left(10,000 \mathrm{~g}, 4^{\circ} \mathrm{C}\right)$. Upper aqueous layer was recovered and mixed with $500 \mu \mathrm{L}$ isopropanol. Each sample was incubated for $10 \mathrm{~min}$ at room temperature and centrifuged again $\left(10 \mathrm{~min}, 10,000 \mathrm{~g}, 4^{\circ} \mathrm{C}\right)$. $500 \mu \mathrm{L}$ of ethanol $70 \%$ was added to the recovered pellets and left for a 3 min ethanol evaporation. Each sample was resuspended in $15 \mu \mathrm{L}$ milliQ water. RNA concentration and integrity was assessed by a NanoDrop ND-100 system. cDNA was obtained using a SuperScript ${ }^{\circledR}$ II reverse transcriptase (Invitrogen). Primers used for PCR were as follows: human MAS1 5'-TGTTGTTGAGGAACCCACGA-3' and 5'-TTCTCATCCGGAAGCACAGG-3' (161-bp product); human ACTB ( $\beta$-actin) primers, 5'-TCCCTGGAGAAGAGCTACGA-3' and 5'-ATCTGCTGGAAGGTGGACAG-3' (362-bp product).

PCR was performed using the following parameters: $95^{\circ} \mathrm{C}$ for $5 \mathrm{~min}, 40$ cycles at $95^{\circ} \mathrm{C}$ for $30 \mathrm{~s}, 58^{\circ} \mathrm{C}$ for $30 \mathrm{~s}$ and $72^{\circ} \mathrm{C}$ for $1 \mathrm{~min}$, followed by a final extension step at $72^{\circ} \mathrm{C}$ for 5 $\mathrm{min}$. The mixture was electrophoretically separated on a $1.5 \%$ agarose gel.

\section{SDS-PAGE and inmunoblotting}

For Western blot, sperm cells were separated in a unique centrifugation step (1800 g, $15 \mathrm{~min})$, as means of washing the seminal plasma, and resuspended in PBS at a minimum concentration of $30 \times 10^{6}$ cells $/ \mathrm{mL}$. The pellets of sperm cells from incubation assays were diluted on lysis buffer, containing RIPA, with different protease, DNase and phosphatase inhibitor cocktail.

For the characterization of the MAS receptor in human spermatozoa, sperm cell pellets were left unfreeze at room temperature and mixed with lysis buffer. The mix was put 
on ice, in constant agitation, for $30 \mathrm{~min}$. The samples were sonicated in a $2 \times 15$ pulse (Amplitude 40, 0.5 cycles), plus other 15 pulse (Amplitude 70, 0.5 cycle) sequence, with $20 \mathrm{~s}$ of repose between each sonication step and then centrifuged $(14,500 \mathrm{~g}, 15 \mathrm{~min})$ and the supernatants were recovered. Proteins (sperm, $\sim 1 \times 10^{6}$ cells/lane; kidney, $30 \mathrm{~g}$ ) were boiled and then were loaded onto $12 \%$ resolving gels and separated by 1D SDS-PAGE. Proteins were then transferred to polyvinylidene fluoride membranes (AmershamTM HybondTM), using the Mini Trans-Blot electrophoretic transfer system (Bio-Rad Laboratories). Blotted membranes were incubated after $1 \mathrm{~h}$ blocking, at $4^{\circ} \mathrm{C}$, overnight, with primary anti-MASR1 polyclonal antiserum (dilution 1:200, Alomone Labs ${ }^{\circledR}$, Jerusalem, Israel). Human kidney extract was used as a positive control.

For the detection and quantification of phospho-AKT in agonist/antagonist incubated sperm cell samples, we used a similar sample-preparation protocol. A 1:300 dilution for rabbit anti (Ser473) phospho-AKT1 primary MAB serum (MerckMillipore) was used. For both MAS1 receptor and phospho-AKT detection assays, HRP-conjugated antirabbit IGG antiserum dilutions (1:1000 and 1:3000, Cell Signalling Technology) were used. The chemiluminiscence analysis was performed in a BioRad's Chemidoc gel analysis system and Quantity One software.

\section{Inmunofluorescence}

For inmunofluorescence assays, sperm cells were isolated by two following centrifugations at low speed (1800g, 15 min.; $1600 \mathrm{~g}, 7 \mathrm{~min}$ ), with a PBS resuspension in between, to remove the seminal plasma. The sperm cell pellets were resuspended in PBS buffer to get an approximate concentration of $30 \times 106$ cells $/ \mathrm{mL}$. To get the capacitated spermatozoa, they were selected by a swim-up procedure and resuspended in G-IVF supplemented with 1\% BSA for 3 h at $37^{\circ} \mathrm{C}$ under $5 \% \mathrm{CO}_{2}$.

In order to localize MASR1 on sperm cell surface, cells suspended in PBS were smeared onto a slide coated with poly-I-lysine and were fixed with $4 \%$ paraformaldehyde for $10 \mathrm{~min}$. Slides were incubated in Triton X100 (1\%) for $10 \mathrm{~min}$ at room temperature to permeabilize cell membranes. Slides were then washed three times in PBS and incubated for 30 min in PBS/10\% ( $\mathrm{vol} / \mathrm{vol}$ ) bovine fetal serum. For indirect immunofluorescence staining, slides were incubated with anti-MASR1 antiserum (Alomone Labs ${ }^{\circledR}$, Jerusalem, Israel) at a dilution of $1: 100$ overnight at $4^{\circ} \mathrm{C}$. Slides were then washed in PBS three times, incubated with Alexa Fluor 488 goat antirabbit IgG secondary antibody (Dilution 1:500, Molecular Probes) for $2 \mathrm{~h}$ at $37^{\circ} \mathrm{C}$ in the dark, washed in PBS three times (in some cases, we stained the nuclei with Hoechst 33342 during the second wash), assembled with Fluoromount G (EMS, Hatfield, UK), and finally examined by confocal microscopy. Negative controls were performed in the same way, except for omission of the primary antibody before secondary antibody addition. Positive control slides were prepared, using the control peptide preparation purchased by Alomone, along with the primary antibody. Cell nucleuses were stained with Hoechst Staining Reagent.

\section{Sperm motility analysis}

Motility analysis was conducted by computer-assisted sperm analysis (Sperm Class Analyzer) at time 0, 10, 30 and 60 min after drug addition to the medium (PBS as vehicle for control, Ang-(1-7) $10^{-7} \mathrm{M}$, Ang-(1-7) $10^{-7} \mathrm{M}+\mathrm{A} 77910^{-6} \mathrm{M}$, and A779 $\left.10^{-6} \mathrm{M}\right)$. Setting parameters and the definition of measured sperm motion parameters for computer-assisted sperm analysis were established by the manufacturer: number of frames to analyze, 25; number of frames/sec, 25; straightness threshold, $80 \%$; cell size range (low), 2; cell size range (high), 60; volume, at least $3.0 \mathrm{~mL}$; sperm concentration $/ \mathrm{mL}$, at least $20 \times 10^{6}$; forward motility, at least $60 \%$. To measure both sperm concentration and motility, aliquots of semen samples $(10 \mu \mathrm{L})$ were placed into a prewarmed $\left(37^{\circ} \mathrm{C}\right)$ Makler counting chamber (Sefi Medical Instruments, Haifa, Israel). For each repetition, five movies of $1 \mathrm{~s}$ (50-100 moving spermatozoa) were recorded in different fields on the top of the drop from at least two different drops of each sample from each specimen. The sperm motility descriptors that we examined were as described by Mortimer (2000): (i) VCL, curvilinear velocity (the instantaneously recorded sequential progression along the entire trajectory of the sperm, measured in $\mu \mathrm{m} \mathrm{s}^{-1}$ ); (ii) VSL, straight line velocity (the straight trajectory of sperm per unit of time, measured in $\mu \mathrm{m} \mathrm{s}^{-1}$ ); (iii) VAP, mean velocity (the mean trajectory of sperm per unit of time, measured in $\mu \mathrm{m} \mathrm{s}^{-1}$ ); (iv) LIN, linearity (defined as $(\mathrm{VSL} / \mathrm{VCL}) \times 100)$; (v) STR, straightness (defined as (VSL/VAP) $\times 100)$; (vi) WOB, wobble or oscillation coefficient (defined as (VAP/VCL) $\times 100$ ); (vii) amplitude of head lateral movement (ALH), which is the head displacement along its curvilinear trajectory around the mean trajectory, measured in $\mu \mathrm{m}$ and (viii) beat cross frequency (BCF), the number of lateral oscillatory movements of the sperm head around the mean trajectory, measured in Hz. Moreover, per cent motile spermatozoa being defined as follows: progressive motility (velocity $\geq 35 \mu \mathrm{m} / \mathrm{s}$ at $37^{\circ} \mathrm{C}$ ), non-progressive motility (velocity $<35 \mu \mathrm{m} / \mathrm{s}$ at $37^{\circ} \mathrm{C}$ ) and immobile.

\section{Sperm acrosome reaction analysis}

Spermatozoa were selected by a swim-up procedure and resuspended in G-IVF supplemented with $1 \%$ BSA for $3 \mathrm{~h}$ at $37^{\circ} \mathrm{C}$ under $5 \% \mathrm{CO}_{2}$ to take place the capacitation (UrizarArenaza et al. 2016). Acrosome reaction was measured by flow cytometry after $1 \mathrm{~h}$ of drug addition to the medium (PBS as vehicle for control, Ang-(1-7) $10^{-7} \mathrm{M}$, Ang-(1-7) $10^{-7}$ $\mathrm{M}+\mathrm{A} 77910^{-6} \mathrm{M}$, and A779 $\left.10^{-6} \mathrm{M}\right)$. We used Fluorescein IsoTioCyanate (FITC) antihuman CD46 (for $60 \mathrm{~min}$ at room temperature; BioLegend, CA, USA) and Hoechst 33258 (2 min at room temperature; Sigma-Aldrich) as acrosome reaction molecular marker and viability dyes respectively. Samples were checked visually by confocal microscopy to verify the signal of the dyes. Green positive cells represented acrosomereacted spermatozoa. Fluorescence data from at least 100,000 events were analyzed in a flow cytometer (FACScalibur; Becton Dickinson, San Jose, CA, USA). To ensure fluorescence data were from live spermatozoa, the percentage of Hoechst 33258-positive events was determined by subtraction of background fluorescence in each histogram. Histograms were 
analysed using the Summit v4.3 software (Beckman Coulter, CA, USA).

\section{Statistical analysis}

Results shown represent mean \pm S.E.M. Statistical analysis was performed by ANOVA with a post hoc analysis by the least significant difference $t$ test. Differences were considered significant for $P$ values of $<0.05$.

\section{Results}

\section{RT-PCR analysis of MAS receptor $m R N A$ in human spermatozoa}

We detected the presence of MAS receptor transcript in human spermatozoa using RT-PCR. The expected 161bp fragment for the Mas was detected also in samples of human kidney (positive control). The housekeeping gene $A C T B$ was detected in all tissues. Finally, retrotranscriptase-negative controls show the absence of genomic DNA in the used samples (Fig. 1A).

\section{Immunoidentification of MAS protein in human spermatozoa}

To check the presence of MAS receptor, the Fig. 1B shows representative Western blot using human spermatozoa and human kidney (positive control). The anti-MAS receptor polyclonal antiserum labeled major two bands at around 40 and $45 \mathrm{kDa}$ both in spermatozoa and in positive control. We also found a band around $30 \mathrm{kDa}$ in kidney protein extract.

\section{Immunocytochemical localization of MAS in human spermatozoa}

Immunofluorescence analysis revealed that MAS receptor was present in the human spermatozoa. The main labeling was detected in the sperm head, over the acrosomal region and in the flagellum. On the contrary, neither in the postacrosomal region nor in the neck was any signal detected (Fig. 1C). When the antibodies were blocked with the specific peptide before addition to the sperm sample, no specific fluorescence was observed (Fig. 1C). Finally, when primary antiserum was omitted before secondary antibody addition, no specific fluorescence was observed (data not shown). When the spermatozoa were capacitated, the immunostaining did not vary (Fig. 1D).

\section{Effect of MAS agonist angiotensin-(1-7) (Ang-(1-7)) and/or the antagonist A779 on AKT phosphorylation in human spermatozoa}

To investigate if Ang-(1-7) induces the activation of AKT, we evaluated the effect of the in vitro incubation of spermatozoa with Ang-(1-7) on AKT phosphorylation at different concentrations $(0.01-1 \mu \mathrm{M})$ and different times
A

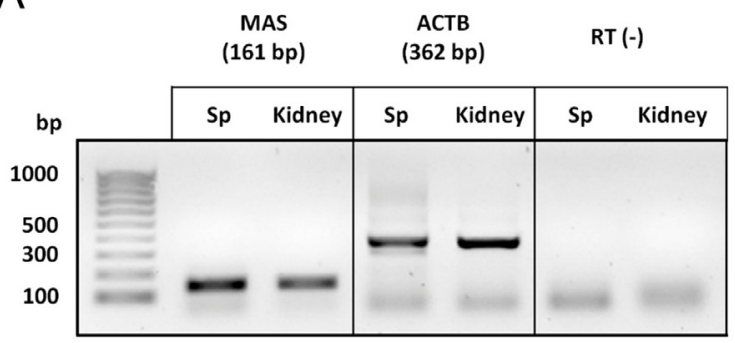

C

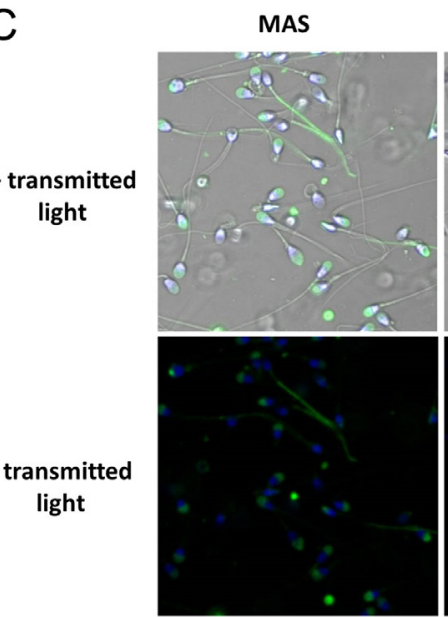

Blocking Peptide

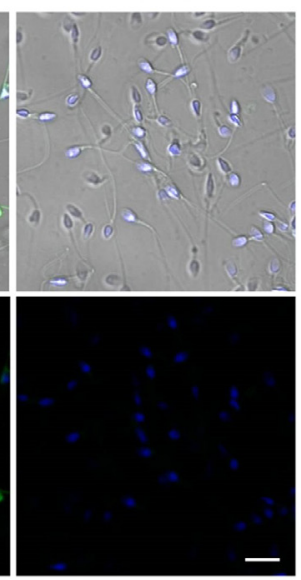

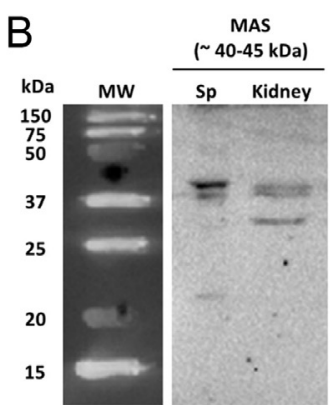

MAS - Capacitated Sp

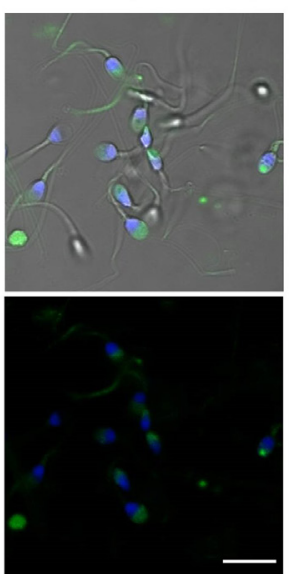

Figure 1 (A) mRNA expression of MAS1 receptor and $\beta$-Actin (ACTB) in human spermatozoa (Sp) and kidney. MAS1 amplified fragment using primers specific for the human MAS1 receptor (161 bp band). ACTB was used as endogenous control (362 bp). A representative RT-PCR experiment is shown; $n=3$. (B) Western blotting analysis of MAS1 receptor in human spermatozoa (Sp) and human kidney using a rabbit antiserum against the the MAS1 receptor protein. Molecular weights (MW-kDa) are indicated on the left. A representative Western blot of those obtained with three normozoospermic donors is shown. (C) Immunofluorescence analysis of MAS1 receptor in human spermatozoa. The negative control consisting of preadsorption of primary antibody with the specific blocking peptide. (D) Immunofluorescence analysis of MAS1 receptor in human capacitated spermatozoa (Sp). MAS1 staining is shown in green. Hoechst-labeled DNA is shown in blue. $n=5$. Representative photomicrographs are shown. The scale bar represents $10 \mu \mathrm{m}$. 
A
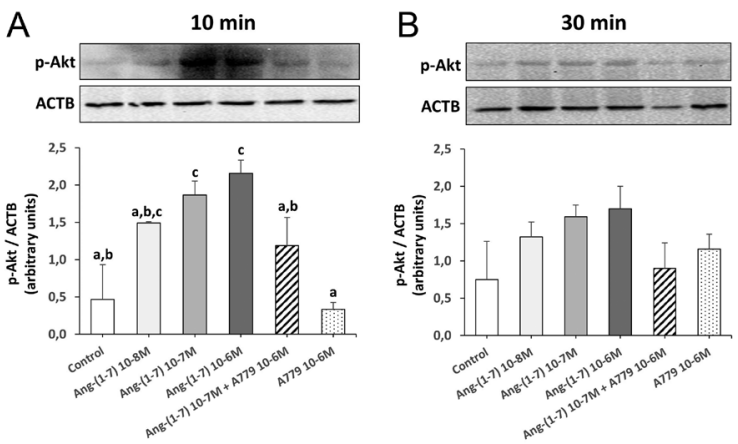

Figure 2 Effect of MAS1 agonist angiotensin-(1-7) (Ang-(1-7)) and/or the antagonist A779 on AKT phosphorylation in human sperm. (A) Dose-response experiment after 10 min of incubation with Ang-(1-7) at 0 , $10^{-8}, 10^{-7}$ and $10^{-6} \mathrm{M}$; blocking experiment after 10 min of incubation with Ang-(1-7) at $10^{-7} \mathrm{M}$ and $\mathrm{A} 779$ at $10^{-6} \mathrm{M}$; control experiment after $10 \mathrm{~min}$ of incubation with A779 alone at $10^{-6} \mathrm{M}$. (B) The same experimentation after 30 min of incubation. (C) The same experimentation after $60 \mathrm{~min}$ of incubation. To determine $\mathrm{p}$-AKT protein abundance, the same extracts were reblotting with anti-ACTB. The histogram shows the p-AKT mean \pm S.E.M. of three different experiments corrected by ACTB content. Significant differences between treatments are indicated with different letters; $P<0.01$ in all cases. $n=3$.
(10, 30 and 60 min). As shown in Fig. 2A, Ang-(1-7) induced the phosphorylation of AKT at dose-dependent manner after 10-min incubation. The MAS receptor antagonist, A779, blocked the stimulating effect of Ang-(1-7) on AKT phosphorylation. The administration of the MAS antagonist by itself did not affect the phosphorylation of AKT. The incubation during $30 \mathrm{~min}$ (Fig. 2B) and $1 \mathrm{~h}$ (Fig. 2C) did not show any significant difference between the treatments. Protein loading in gels was evaluated and corrected by reblotting membranes with anti- $\beta$-actin (ACTB) antibody $(n=3$ for each time and condition).

\section{Sperm motility after the in vitro incubation with MAS agonist angiotensin-(1-7) (Ang-(1-7)) and/or the antagonist A779}

We analyzed motility parameters related to progressivity of spermatozoa and we see how the incubation of sperm cells, from normal motility samples (total motility $\geq 40 \%$; progressive motility $\geq 32 \%$ ) (WHO 2010), with MAS agonist and/or antagonist did not modify significantly any of the percentage of sperm cells during the tested times (Fig. 3A). Conversely, using sperm cells from astenozoospermic patients (total
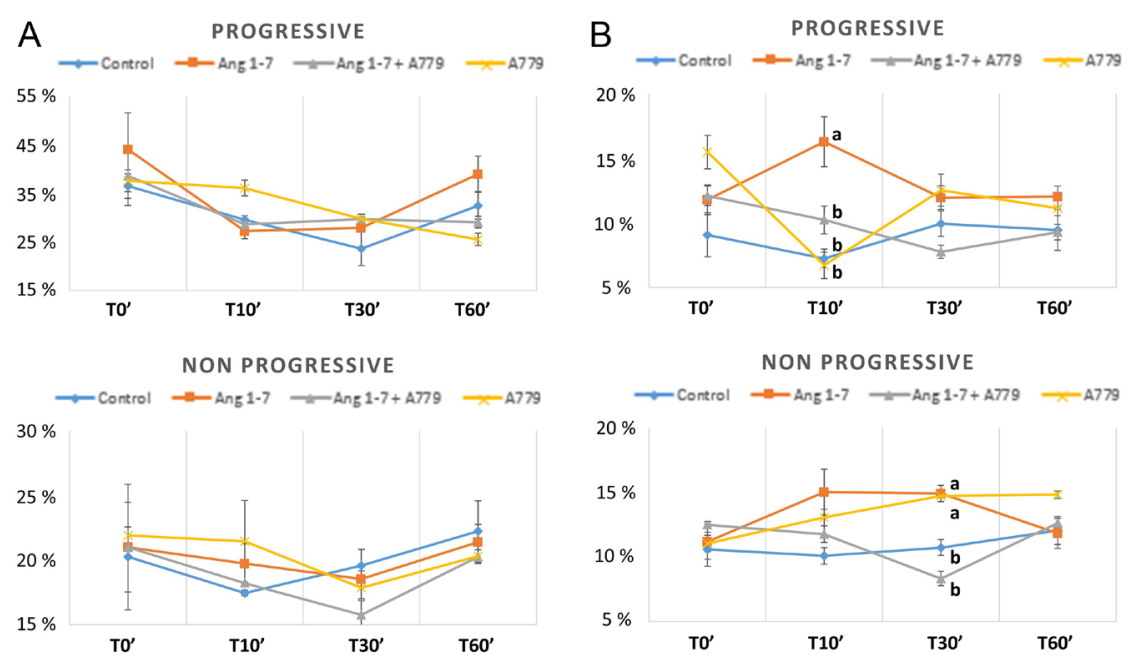

IMMOTILE
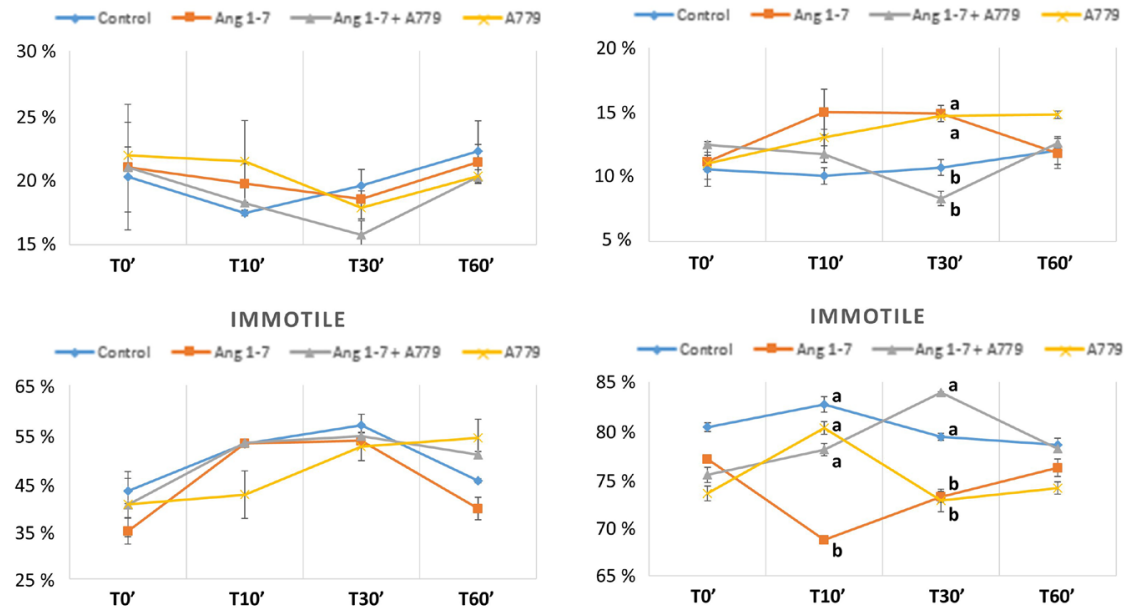

Figure 3 Effect of incubation with MAS agonist and/or antagonist on sperm motility. Comparison of sperm cell \% divided in progressive motility, non-progressive motility and immotility after incubation at $0,10 \mathrm{~min}$, $30 \mathrm{~min}$ and $60 \mathrm{~min}$ with angiotensin-(1-7) (Ang-(1-7)) $10^{-7} \mathrm{M}$ (orange), Ang-(1-7) $10^{-7}$ $\mathrm{M}+\mathrm{A} 77910^{-6} \mathrm{M}$ (grey), A779 alone $10^{-6} \mathrm{M}$ (yellow) and control (blue) for (A) normal motility samples and (B) asthenozoospermic samples. Significant differences between treatments are indicated with different letters. $P<0.01 . n=8$ independent donor for each condition. 
motility $<40 \%$; progressive motility $<32 \%$ ), the MAS receptor agonist Ang-(1-7) (at $10^{-7} \mathrm{M}$ ) increased the percentage of progressive mobile spermatozoa at 10 min of incubation (Fig. 3B), whereas the percentage of immotile cells decreased (Fig. 3B). The differences were significant compared to all other treatments: control, Ang-(1-7) $\left(10^{-7} \mathrm{M}\right)+\mathrm{A} 779\left(10^{-6} \mathrm{M}\right)$ and A779 $\left(10^{-6} \mathrm{M}\right)$ alone (Fig. 3B). At $30 \mathrm{~min}$ of incubation, the percentage of progressive mobile cells decreased in the samples incubated with the agonist and, consequently, the percentage of progressive motile cells for all treatments was equalized (Fig. 3B). On the other hand, while the number of immobile spermatozoa increased for the samples incubated with the agonist, there was a significant difference of motile cells (non-progressive) in comparison with the control and with the samples co-incubated with the agonist and the antagonist (Fig. $3 \mathrm{~B})$. In this case, the samples incubated only with the antagonist showed the same percentages as the samples treated with the agonist (Fig. 3B). Finally, after $60 \mathrm{~min}$ of incubation, the motility percentages for all treatments were equalized (Fig. 3B).

\section{MAS protein quantity and the effect of MAS agonist/ antagonist on p-AKT in asthenozoospermic patients' spermatozoa}

When we semi-quantitatively compared the amount of MAS receptor between samples of normozoospermic and astenozoospermic patients, we saw that there were no significant differences between the two populations (Fig. 4A). On the other hand, spermatozoa from asthenozoospermic patients showed the same pattern of phosphorylation of AKT at 10 min of incubation with the agonist Ang- $(1-7)\left(10^{-7} \mathrm{M}\right)$ and, although the antagonist A779 $\left(10^{-7} \mathrm{M}\right)$ did not generate any phosphorylation signal, it was not able to block the effect of the agonist when when they were incubated together (Fig. 4B).

\section{Sperm acrosome reaction after the in vitro incubation with MAS agonist angiotensin-(1-7) (Ang-(1-7)) and/or the antagonist $A 779$}

The incubation of sperm cells with Ang-(1-7) did not change the percentage of acrosome-reacted cells compared to the control (Fig. 5). Likewise, none of the other treatments performed (co-incubation of agonist and antagonist or the antagonist alone) generated differences in relation to the percentage of acrosomereacted cells compared to the control (Fig. 5).

\section{Discussion}

The presence of the ACE/AngII/AT1R and AT2R axis has been described in male reproductive system and some physiological roles have been suggested for those compounds (Vinson et al. 1996, Passos-Silva et al. 2013,

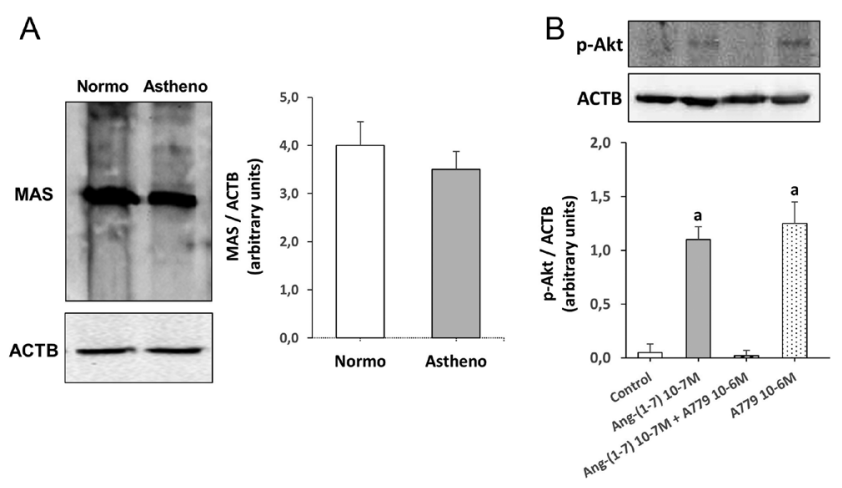

Figure 4 MAS1 protein quantity and the effect of MAS1 agonist/ antagonist on p-AKT in asthenozoospermic patients' spermatozoa. (A) Western blotting analysis of MAS1 receptor in normozoospermic samples (Normo) and asthenozoospermic samples (Astheno) using a rabbit antiserum against the MAS1 receptor protein. The graph shows the MAS1 mean \pm S.E.M. of three different experiments corrected by ACTB content. A representative Western blot of those obtained with three donors is shown. (B) Effect of MAS1 agonist angiotensin-(1-7) (Ang-(1-7)) and/or the antagonist A779 on AKT phosphorylation in asthenozoospermic sperm after 10 min of incubation with Ang-(1-7) at $10^{-7}$; blocking experiment after $10 \mathrm{~min}$ of incubation with Ang-(1-7) at $10^{-7} \mathrm{M}$ and $\mathrm{A} 779$ at $10^{-6} \mathrm{M}$; control experiment after 10 min of incubation with $\mathrm{A} 779$ alone at $10^{-6} \mathrm{M}$. To determine p-AKT protein abundance, the same extracts were reblotting with antiACTB. The graph shows the p-AKT mean \pm S.E.M. of three different experiments corrected by ACTB content. Significant differences between treatments are indicated with different letters; $P<0.01$ in all cases. $n=3$.

Gianzo et al. 2016) However, there are few studies regarding the ACE2/Ang-(1-7)/MAS axis. It has been observed that men with spermatogenesis impairment have lower levels of the compounds of that axis when they are compared with fertile subjects (Reis et al. 2010), but it is not known if MAS receptor is present in sperm cells, if it is active or what could be its function. Therefore, in our present work, we have verified the presence of the MAS receptor in human mature spermatozoa, not only at the mRNA level but also at protein level. Moreover, we have elucidated that the sperm incubation with the

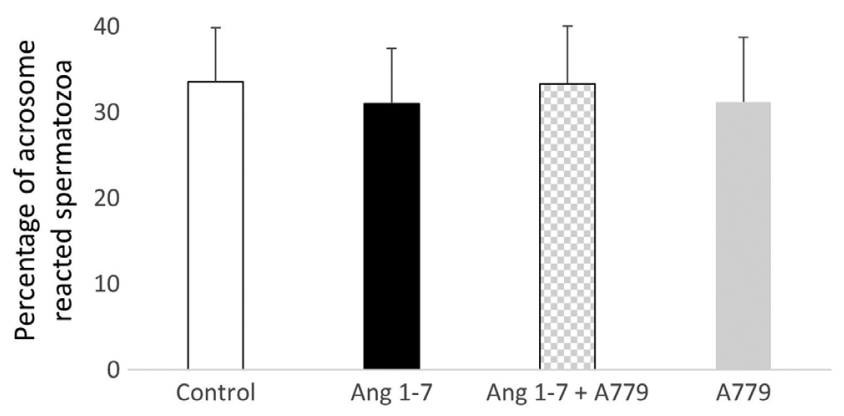

Figure 5 Effect of incubation with MAS agonist and/or antagonist on sperm acrosome reaction. Acrosome-reacted sperm cell \% after incubation with angiotensin-(1-7) (Ang-(1-7)) $10^{-7} \mathrm{M}$ (black), Ang-(1-7) $10^{-7} \mathrm{M}+\mathrm{A} 77910^{-6} \mathrm{M}$ (squares), A779 alone $10^{-6} \mathrm{M}$ (grey) and control (withe) for 1 h. $n=8$. 
MAS specific agonist Ang-(1-7) and/or the antagonist A779 activated MAS receptor, modulating the AKT phosphorylation-pattern. In addition, the activation of MAS was able to modulate the sperm motility but not the acrosome reaction.

RT-PCR revealed the presence of MAS mRNA in the human spermatozoa and Western blot analysis revealed the presence of MAS receptor protein in human spermatozoa. We detected two bands of about 40 and $45 \mathrm{kDa}$ in spermatozoa and in the kidney cells, used as positive control, which accords in size with the certificate of analysis of the manufacturer and previous reports (Olivon et al. 2015, Ali et al. 2016).

Immunofluorescence analysis revealed the presence of the MAS protein in the human sperm head with more intensity at the acrosomal region, but also in the tail. Due to the highly polarized structure and function of spermatozoa, they require the compartmentalization of particular metabolic and signaling pathways to specific regions (Aquila et al. 2004) and that was the reason why it would be interesting to test if the MAS receptor was related to a possible function in the motility or the acrosome reaction, as it has been seen in other works carried out with different compounds (Agirregoitia et al. 2006, 2010).

Even so, firstly, we needed to know if the MAS receptor in spermatozoa was functionally active or not. For this purpose, we carried out agonism/antagonism experiments to observe the phosphorylation pattern of AKT kinase, since it has been reported that Ang(1-7) phosphorylates the PI3K/AKT pathway via the MAS receptor (Giani et al. 2007, Sampaio et al. 2007). We verified that MAS agonist Ang-(1-7) induced the phosphorylation of AKT at dose-dependent manner after 10-min incubation, as it has been previously described for other tissues (Giani et al. 2007, Sampaio et al. 2007). In addition, the MAS receptor antagonist, A779, blocked the stimulating effect of Ang-(1-7) on AKT phosphorylation, a fact that has been observed in other tissues and that led to the conclusion that the MAS receptor was active in said tissues (Muñoz et al. 2010). Although the presence of the agonist during $30 \mathrm{~min}$ of incubation seemed to show a positive trend in the level of phosphorylation of AKT, this variation was not really significant. Finally, the phosphorylation rate it is not different from the control after $1 \mathrm{~h}$ of incubation. Thus, it seems that the MAS receptor present in the spermatozoa is functionally active and, for the following experiments, we used one of the agonist concentration that mostly phosphorylated the AKT $\left(10^{-7} \mathrm{M}\right)$.

Once the activity of the MAS receptor in the mature spermatozoa was verified, we carried out experiments to observe the effect of the activation of the receptor on the sperm mobility. Spermatozoa mature during epididymal transit due to a series of morphological, biochemical and physiological changes. Once human spermatozoa, in seminal plasma, are deposited in the vagina, they must swim through the cervical mucus, traverse the uterus, enter the oviduct and finally bind to the oocyte if they have been 'capacitated' during transport through the female reproductive tract (Yanagimachi 1994). Sperm motility patterns associated with each of these mentioned regions differ due to differences in the physical and chemical composition of the micro-environments encountered by the spermatozoa (Mortimer 1997) . Even so, when sperm motility is lower than recommended, as in asthenozoospermic patients, problems in the ability to fertilize may occur (Mortimer 2000). As we have observed, the proportion of progressive motile spermatozoa increased by the incubation of spermatozoa of astenozoospermic patients with the selective Mas receptor agonist Ang(1-7), a fact that was blocked by the antagonist A779. This observation coincides with the previous studies where it was described that the phosphorylation of Akt increases the number of motile and progressive motile spermatozoa (Sagare-Patil et al. 2013, Zhang et al. 2017). At the used concentration, Ang-(1-7) was able to improve the sperm motility via Akt from 10 to $30 \mathrm{~min}$. Even so, it did not generate changes in any of the other sperm kinematics analyzed (Supplementary Fig. 1, see section on supplementary materials given at the end of this article).

Once these results were known, we wanted to investigate if there was any difference between normozoospermic and asthenozoospermic samples, but the amount of MAS receptor between both samples did not vary. Moreover, the location of MAS in spermatozoa of asthenozoospermic samples did not vary in comparison with normal motility samples (data not shwon). Finally, the Ang-(1-7) itself was also able to phosphorylate the AKT as well as in the normozoospermic ones, but we found a difference: the A779 antagonist was not able to block the effect of the agonist on the astenozoospermic samples, as we observed in the normozoospermic samples. This leads us to think that there could be some action of the Ang-(1-7) by another receptor that was not MAS in the sperm defined as astenozoospermic, since it has been recently described that the Ang-(1-7) is also able to bind to MRGPRD (MAS1-related GPCR) and AT2 (Angll type 2) receptors, and maybe AT1 (Karnik et al. 2017).

Finally, in the experiments performed to see if the activation of the MAS receptor was able to modify the amount of acrosome-reacted sperm cells, we did not observe any difference between the treated spermatozoa and the control. Therefore, it seems that, at least at the concentration and times used, the MAS receptor is also not able to modulate, by activating the AKT, the acrosome reaction, as has been described previously for other compounds and receptors (Sagare-Patil et al. 2013). Even so, as with other substrates, it cannot be ruled out that it could act as a modulator of the acrosome reaction triggered by other stimuli (Xu et al. 2017). 
In conclusion, we report for first time the presence of functional MAS receptors in human spermatozoa and we show that its activation participates in regulating sperm motility of asthenozoospermic patients. These findings suggest that the ACE2/Ang-(1-7)/MAS axis may be a useful biochemical tool for the treatment of male infertility, although more experiments with animal models will be necessary to elucidate whether the modulation of this axis of communication really has a future in the reproduction field.

\section{Supplementary materials}

This is linked to the online version of the paper at https://doi. org/10.1530/REP-19-0274.

\section{Declaration of interest}

The authors declare that there is no conflict of interest that could be perceived as prejudicing the impartiality of the research reported.

\section{Funding}

This work received financial support from the University of the Basque Country (Grants GIU14/26 and GIU17/19). L T acknowledges the financial support given by University of the Basque Country (PIF15/149).

\section{Author contribution statement}

Conceptualization and designed the experiments: A V, I I and $\mathrm{E} A$; patient collection and sample classification: $\mathrm{B} C$ and $\mathrm{R} M$; Methodology and Investigation: RT-PCR, L T; Western blot, A V, L Co, M B; immunocytochemistry, N A; Sperm motility, A V, $\mathrm{L} C \mathrm{C}$ and $\mathrm{L} C \mathrm{Ca}$; acrosome reaction $\mathrm{LT}$ and $\mathrm{NA}$; wrote the first draft of the manuscript. A V, J I and E A; editing and revising the manuscript, $\mathrm{L} C \mathrm{C}$; supervision of the project, $\mathrm{A} \vee$ and $\mathrm{E} A$.

\section{Acknowledgments}

The authors thank SGiker (UPV/EHU) for personal and technical support, particularly Ricardo Andrade and Alejandro Díez for his assistance with the confocal microscopy and flow cytometry analysis. Authors want to thank also Arantza Perez Dobaran and Itziar Urizar-Arenaza for their technical support.

\section{References}

Agirregoitia E, Valdivia A, Carracedo A, Casis L, Gil J, Subiran N, Ochoa C \& Irazusta J 2006 Expression and localization of $\delta$-, $\kappa$-, and $\mu$-opioid receptors in human spermatozoa and implications for sperm motility. Journal of Clinical Endocrinology and Metabolism 91 4969-4975. (https://doi.org/10.1210/jc.2006-0599)

Agirregoitia E, Carracedo A, Subirán N, Valdivia A, Agirregoitia N, Peralta L, Velasco G \& Irazusta J 2010 The $\mathrm{CB}(2)$ cannabinoid receptor regulates human sperm cell motility. Fertility and Sterility 93 1378-1387. (https://doi.org/10.1016/j.fertnstert.2009.01.153)
Ali Q, Dhande I, Samuel P \& Hussain T 2016 Angiotensin type 2 receptor null mice express reduced levels of renal angiotensin II type 2 receptor/ angiotensin (1-7)/Mas receptor and exhibit greater high-fat diet-induced kidney injury. Journal of the Renin-Angiotensin-Aldosterone System $\mathbf{1 7}$ 1470320316661871. (https://doi.org/10.1177/1470320316661871)

Aquila S, Sisci D, Gentile M, Middea E, Catalano S, Carpino A, Rago V \& Andò S 2004 Estrogen receptor (ER) $\alpha$ and ER $\beta$ are both expressed in human ejaculated spermatozoa: evidence of their direct interaction with phosphatidylinositol-3-OH kinase/Akt pathway. Journal of Clinical Endocrinology and Metabolism 89 1443-1451. (https://doi.org/10.1210/ jc.2003-031681)

Giani JF, Gironacci MM, Muñoz MC, Peña C, Turyn D \& Dominici FP 2007 Angiotensin-(1 7) stimulates the phosphorylation of JAK2, IRS-1 and Akt in rat heart in vivo: role of the AT1 and Mas receptors. American Journal of Physiology: Heart and Circulatory Physiology $293 \mathrm{H} 1154-\mathrm{H} 1163$. (https://doi.org/10.1152/ajpheart.01395.2006)

Gianzo M, Muñoa-Hoyos I, Urizar-Arenaza I, Larreategui Z, Quintana F, Garrido N, Subirán N \& Irazusta J 2016 Angiotensin II type 2 receptor is expressed in human sperm cells and is involved in sperm motility. Fertility and Sterility 105 608-616. (https://doi.org/10.1016/j. fertnstert.2015.11.004)

Karnik SS, Singh KD, Tirupula K, Unal H 2017 Significance of angiotensin 1-7 coupling with MAS1 receptor and other GPCRs to the reninangiotensin system: IUPHAR Review 22. Brithis Journal of Pharmacology 174 737-753. (https://doi.org/10.1111/bph.13742)

Leal MC, Pinheiro SVB, Ferreira AJ, Santos RAS, Bordoni LS, Alenina N, Bader M \& França LR 2009 The role of angiotensin-(1-7) receptor Mas in spermatogenesis in mice and rats. Journal of Anatomy 214 736-743. (https://doi.org/10.1111/j.1469-7580.2009.01058.x)

Mortimer ST 1997 A critical review of the physiological importance and analysis of sperm movement in mammals. Human Reproduction Update 3 403-439. (https://doi.org/10.1093/humupd/3.5.403)

Mortimer ST 2000 CASA - practical aspects. Journal of Andrology 21 $515-524$.

Muñoz MC, Giani JF \& Dominici FP 2010 Angiotensin-(1-7) stimulates the phosphorylation of Akt in rat extracardiac tissues in vivo via receptor Mas. Regulatory Peptides 161 1-7. (https://doi.org/10.1016/j. regpep.2010.02.001)

Olivon VC, Aires RD, Santiago LB, Ramalho LZN, Cortes SF \& Lemos VS 2015 Mas receptor overexpression increased Ang-(1-7) relaxation response in renovascular hypertensive rat carotid. Peptides 71 250-258. (https://doi.org/10.1016/j.peptides.2015.08.002)

Passos-Silva DG, Verano-Braga T \& Santos RAS 2013 Angiotensin-(1-7): beyond the cardio-renal actions. Clinical Science 124 443-456. (https:// doi.org/10.1042/CS20120461)

Reis AB, Araújo FC, Pereira VM, Dos Reis AM, Santos RA \& Reis FM 2010 Angiotensin (1-7) and its receptor Mas are expressed in the human testis: implications for male infertility. Journal of Molecular Histology $4 \mathbf{1}$ 75-80. (https://doi.org/10.1007/s10735-010-9264-8)

Sagare-Patil V, Vernekar M, Galvankar M \& Modi D 2013 Progesterone utilizes the PI3K-AKT pathway in human spermatozoa to regulate motility and hyperactivation but not acrosome reaction. Molecular and Cellular Endocrinology 374 82-91. (https://doi.org/10.1016/j. mce.2013.04.005)

Sampaio WO, Souza dos Santos RA, Faria-Silva R, da Mata Machado LT, Schiffrin EL \& Touyz RM 2007 Angiotensin-(1-7) through receptor Mas mediates endothelial nitric oxide synthase activation via Akt-dependent pathways. Hypertension 49 185-192. (https://doi.org/10.1161/01. HYP.0000251865.35728.2f)

Santos RA, e Silva ACS, Maric C, Silva DMR, Machado RP, de Buhr I, Heringer-Walther S, Pinheiro SVB, Lopes MT, Bader M et al. 2003 Angiotensin-(1-7) is an endogenous ligand for the $G$ protein-coupled receptor Mas. PNAS 100 8258-8263. (https://doi.org/10.1073/ pnas.1432869100)

Urizar-Arenaza I, Estomba H, Muñoa-Hoyos I, Matorras R, Esposito A, Candenas L, Pinto FM, Valdivia A, Irazusta J, Subirán N 2016 The opioid peptide beta-endorphin stimulates acrosome reaction in human spermatozoa. Andrology 4 143-151. (https://doi.org/10.1111/ andr.12133)

Vinson GP, Mehta J, Evans S, Matthews S, Puddefoot JR, Saridogan E, Holt W V \& Djahanbakhch O 1996 Angiotensin II stimulates sperm motility. Regulatory Peptides 67 131-135. (https://doi.org/10.1016/ S0167-0115(96)00118-8) 
WHO 2010 WHO Laboratory Manual for the Examination and Processing of Human Semen. Geneva: World Health Organization.

Xu W, Wang K, Chen Y, Liang XT, Yu MK, Yue H, Tierney ML 2017 Sperm gamma-aminobutyric acid type $A$ receptor delta subunit (GABRD) and its interaction with purinergic P2X2 receptors in progesteroneinduced acrosome reaction and male fertility. Reproduction Fertiliti and Development 10 2060-2072. (https://doi.org/10.1071/RD16294)

Yanagimachi R 1994 Mammalian fertilization. In The Physiology of Reproduction, 2nd ed., pp 189-317. Eds E Knobil \& JD Neill. New York: Raven Press Ltd.

Zhang J, Zhang X, Liu Y, Su Z, Dawar FU, Dan H, He Y, Gui J-F \& Mei J 2017 Leucine mediates autophagosome-lysosome fusion and improves sperm motility by activating the PI3K/Akt pathway. Oncotarget 8 111807-111818. (https://doi.org/10.18632/oncotarget.22910)

Received 24 June 2019

First decision 24 July 2019

Revised manuscript received 18 December 2019

Accepted 22 December 2019 